\title{
Comparision of how old age psychiatry and general adult psychiatry services meet the needs of elderly people with functional mental illness: cross-sectional survey ${ }^{\dagger}$
}

\author{
Walid Khalid Abdul-Hamid, Kelly Lewis-Cole, Frank Holloway and Ann Marisa Silverman
}

\section{Background}

There is little research evidence as to whether general adult psychiatry or old age psychiatry should look after old people with enduring mental illness.

\section{Aims \\ To compare the extent to which general adult and old age psychiatric services meet the needs of older people with} enduring mental illness.

\section{Method}

A total of 74 elderly patients with functional psychiatric disorders were identified by reviewing the notes of patients over the age of 60 living in a defined inner urban catchment area. Data were collected on the morbidity and needs of the sample. Needs were assessed using the Elderly Psychiatric Needs Schedule (EPNS)

\section{Results}

The participants in contact with old age psychiatry had significantly fewer unmet needs compared with those in contact with general adult psychiatry (2.8 v. 5.6, $t=2.2$, $P<0.03)$. Total needs were not significantly different between those managed by old age and general adult services $(8.0 \mathrm{~V}$. 6.5 respectively, $t=1.2, P=0.2$ )

\section{Conclusions}

This study found that old age psychiatry services were better placed to meet the needs of elderly people with mental illness. This finding supports the need for a separate old age psychiatry service.

\section{Declaration of interest}

None.

\section{Copyright and usage}

(c) The Royal college of Psychiatrists 2015.
In spite of the fact that the UK was one of the first countries to develop specialist old age services, since the economic crisis and the restructuring of the National Health Service (NHS) the situation has started to change. There has been a drive to create 'age inclusive' mental health to address the needs of people regardless of their age. However, authoritative voices have expressed concern that an ageless service might well cause even more discrimination for elderly people if it is not designed to meet their specific needs. ${ }^{1}$ The Royal College of Psychiatrists, together with many other organisations concerned with the care of elderly people who are mentally ill, had asked the government for a halt in the implementation of ageless mental health services. ${ }^{2}$ In spite of this, by 2013 almost $11 \%$ of NHS trusts had already disbanded their old age psychiatry teams. ${ }^{3}$ In 2014 the President of the College wrote to the Minister of State for Care and Support warning of the dangers of treating 18- and 80-year-olds within the same team. ${ }^{4}$

Even before the advent of ageless services there was no coherent policy to determine which services should look after older people with functional mental illness. ${ }^{5}$ This lack of policy may relate to a lack of evidence. A survey of the needs of older people with enduring mental illness identified many unmet needs, ${ }^{6}$ although there are clear problems in using a generic needs assessment tool in an elderly population. ${ }^{7}$ Jolley et al argued that there should be a needs assessment that takes in consideration local services and resources. ${ }^{8}$ The current study reports a survey using a needs assessment schedule that was developed and validated on older people with functional mental illness. ${ }^{9}$ In this

'See editorial, pp. 375-376, this issue. study, we assessed the needs of an epidemiologically based sample of elderly people with functional mental illness in contact with old age psychiatry and general adult psychiatry services to explore which of the two services was better in meeting the needs of these patients.

\section{Method}

The aims of this study were: to undertake a needs assessment of all old people with enduring mental illness in contact with specialist mental health services (both general adult and old age psychiatry services) in a defined catchment area; and to compare the extent to which both services met the needs of this population. The study was carried out in Norwood, an ethnically diverse and socially deprived sector of the then Bethlem and Maudsley Trust catchment area in inner London. Two of the authors were the adult general and old age psychiatry consultants in this sector. The sampling frame of the study population included all patients aged 60 or over with functional mental illness who were in contact with the catchment area psychiatric services and who had the onset of their illness before the age of 60 . Along with patients who were over 65 years of age, a 'pre-elderly' group of patients who were 60-65 years of age was included. Given the chronic and enduring nature of their illnesses this 'pre-elderly' group were highly likely to become 'graduates' of adult services within the succeeding 5 years. More than 300 medical notes of Norwood patients aged 60 or over were reviewed and 77 people with enduring mental illness were identified. The definition of 'graduates' used was that of Arie \& Jolley: ${ }^{10}$ people with severe functional psychiatric disorders who graduate into old age. All patients with organic mental health problems or those with 
functional disorders who only came in contact with psychiatric services after the age of 65 were excluded. In total 64 out of the 77 patients identified were interviewed ( 3 were untraceable). Of these, 40 were in contact with the general adult psychiatry service and 34 were in contact with the old age psychiatry service. These patients and their psychiatric key workers were interviewed separately. Interviews were only started after securing ethical approval. The assessment package consisted of the following questionnaires: (a) Mini-Mental State examination; ${ }^{11}$ (b) the Brief Psychiatric Rating Scale; ${ }^{12}$ (c) the Geriatric Depression Scale; ${ }^{13}$ (d) the Clifton Assessment Procedure for the Elderly (CAPE) $;{ }^{14}$ (e) the Elderly Psychiatric Needs Schedule (EPNS). ${ }^{9}$

Statistical analysis included the following statistical methods: producing simple frequencies of study variables in the sample and hypothesis testing using bivariate analysis of crude rates (using the chi-squared test and $t$-test) generating significance tests in the form of $P$-values and confidence intervals.

\section{Results}

\section{Demographic and clinical features}

Not surprisingly the age groups of the general adult psychiatry group and old age psychiatry group were significantly different. Only $46 \%(n=15)$ of the general adult psychiatry group were aged 65 years and over, whereas $97 \%(n=39)$ of the old age psychiatry group were 65 years and over $\left(\chi^{2}=25, P<0.00001\right)$. The general adult psychiatry group had an equal proportion of men and women, whereas the majority of the old age psychiatry sample $(70 \%, n=28)$ were women (the difference in gender was, however, not statistically significant between the two groups). The marital status of the two groups was similar. The ethnic origin of the sample reflected the age of the two groups and a cohort effect that reflects the changing demography of the sector as there were more White people in the old age psychiatry group $(98 \% \quad(n=39)$ compared with $79 \%(n=27)$ in the general adult psychiatry group). The difference was not statistically significant.

The main clinical diagnosis recorded in patients' hospital notes showed a higher proportion (not statistically significant) of people with schizophrenia among the general adult psychiatry group $(56 \%(n=19)$ compared with $28 \%(n=11)$ in the old age psychiatry group) and a higher proportion (not statistically significant) of people with depression among the old age psychiatry sample $(58 \%(n=23)$ compared with $21 \%(n=7)$ in the general adult psychiatry group).

\section{Comparing needs}

'Total needs' within the EPNS includes both met and unmet needs. It is a measure of disablement and is therefore potentially independent of service provision. ${ }^{15}$ Table 1 shows the distribution of these needs within the old age psychiatry and general adult psychiatry groups. In both groups $100 \%$ had a need for psychiatric assessment and treatment, which is reassuring since people should not be in contact with a psychiatric service if they do not have this need. More people in the general adult psychiatry group (21\%, $n=7)$ needed dementia assessment compared with the old age psychiatry group $(10 \%, n=4)$, although this difference was not statistically significant. This might reflect the higher prevalence of schizophrenia in the general adult psychiatry group. A higher proportion of the general adult psychiatry group needed substance misuse services $(24 \%(n=8)$ compared with $8 \%(n=3)$ in the old age psychiatry group) but this difference was not statistically significant.

The general adult psychiatry group had higher needs for most of the EPNS items but none of them reached statistical significance apart from ethnic and cultural needs $(21 \%(n=7)$ compared with only $5 \%(n=2)$ in the old age psychiatry group). A calculation of the mean total needs in the two groups reflected

Table 1 Comparison of total needs of the old people with enduring mental illness who are in contact with adult general adult and old age psychiatry

\begin{tabular}{|c|c|c|c|}
\hline \multirow[b]{2}{*}{ Elderly Psychiatric Needs Schedule items } & \multicolumn{2}{|c|}{$n(\%)$} & \multirow[b]{2}{*}{$\begin{array}{l}\text { Odds ratio } \\
(95 \% \mathrm{Cl})\end{array}$} \\
\hline & $\begin{array}{l}\text { Old age psychiatry } \\
\qquad(n=34)\end{array}$ & $\begin{array}{l}\text { Adult general psychiatry } \\
\qquad(n=40)\end{array}$ & \\
\hline 1. Psychiatric assessment and treatment needs & $34(100)$ & $40(100)$ & - \\
\hline 2. Dementia assessment and management needs & $4(10)$ & $7(20)$ & $2.3(0.6-8.8)$ \\
\hline 3. Management of medication & $17(43)$ & $13(38)$ & $0.8(0.3-2.1)$ \\
\hline 4. Substance abuse services needs & $3(8)$ & $8(24)$ & $3.8(0.9-16)$ \\
\hline 5. Physical health needs & $19(50)$ & $18(53)$ & $1.2(0.5-3.1)$ \\
\hline 6. Communication needs & $2(5)$ & $6(18)$ & $4.1(0.8-21.7)$ \\
\hline 7. Mobility needs & $16(40)$ & $14(41)$ & $1.05(0.4-2.7)$ \\
\hline 8. Incontinence service need & $9(23)$ & $7(21)$ & $0.9(0.3-2.7)$ \\
\hline 9. Self-care needs & $15(37)$ & $17(50)$ & $1.7(0.7-4.2)$ \\
\hline 10. Domestic management needs & $17(43)$ & $18(53)$ & $1.5(0.6-3.8)$ \\
\hline 11. Food and eating needs & $17(43)$ & $16(47)$ & $1.2(0.5-3.1)$ \\
\hline 12. Safety and protection needs & $10(25)$ & $12(35)$ & $1.6(0.6-4.5)$ \\
\hline 13. Social activity needs & $20(50)$ & $20(59)$ & $1.4(0.6-3.6)$ \\
\hline 14. Day care needs & $22(55)$ & $20(59)$ & $1.2(0.5-2.9)$ \\
\hline 15. Money and benefits needs & $13(33)$ & $11(32)$ & $0.99(0.4-2.6)$ \\
\hline 16. Transport needs & $13(33)$ & $14(41)$ & $1.5(0.6-3.7)$ \\
\hline 17. Housing needs & $9(23)$ & $15(44)$ & $2.7(1.0-7.4)$ \\
\hline 18. Ethnic and cultural needs* & $2(5)$ & $7(21)$ & $4.9(0.9-26)$ \\
\hline 19. Management of patient's affairs & $7(18)$ & $10(29)$ & $1.96(0.7-5.9)$ \\
\hline 20. Other needs & $4(10)$ & $6(18)$ & $1.9(0.5-7.5)$ \\
\hline
\end{tabular}


the same pattern. The mean total needs for the general adult psychiatry group was 8.0 needs compared with 6.5 needs in the old age psychiatry group. There was a non-significant difference between mean total needs for the two groups $(t=1.2, P=0.2)$.

\section{Unmet needs}

Table 2 shows the distribution of unmet needs in the old age psychiatry and general adult psychiatry groups. Unmet need was more common in the general adult psychiatry group across all 20 need domains and statistically significantly so in 6 domains. There were significantly higher unmet needs in the general adult psychiatry group on the management of medication $(29 \%$ $(n=10)$ compared with $10 \%(n=4)$ in the old age psychiatry group); substance misuse service needs $(24 \%(n=8)$ compared with $5 \%(n=2)$ in the old age psychiatry group); physical health needs $(38 \%(n=13)$ compared with $18 \%(n=7)$ in the old age psychiatry group); domestic management needs $(32 \% \quad(n=11)$ compared with $10 \%(n=4)$ in the old age psychiatry group); transport needs $(32 \%(n=11)$ compared with $10 \%(n=4)$ in the old age psychiatry group); and housing needs $(32 \%(n=11)$ compared with $10 \%(n=4)$ in the old age psychiatry group). The general adult psychiatry group had significantly more unmet needs than the old age psychiatry group $(5.6($ s.d.=6.4) v. 2.8 (s.d. =3.4) $t=2.2, P=0.03$ ).

\section{Discussion}

Historically the specialty of old age psychiatry has looked after patients who are frail and vulnerable. In addition to patients who have dementia of any age, the specialty manages patients with functional psychiatric disorders, physical illness and frailty, and also those with psychological and social difficulties associated with old age. ${ }^{3}$ The last two groups contain patients with functional problems who are traditionally known as 'graduates. These two groups are more likely to be looked after by general adult psychiatry under the new ageless services. ${ }^{1}$

\section{Main findings}

In this study we looked in detail at the needs of graduates at the interface between general adult psychiatry and old age psychiatry services. We found that old age psychiatry services were at the time of the study better able to meet the needs of graduates, which goes against the current trend towards 'age-inclusive' services. These patients are at risk of being overlooked in such ageless services, particularly when competing for resources with more disturbed younger patients.

The difference in age and diagnosis between the two groups reflects the nature of the interface between the two services and a cohort effect. Before the advent of 'age-inclusive' services it was usual for people with relapsing psychiatric disorder such as severe affective disorder to move to old age psychiatry services if they have a relapse after the age of 65 following a period out of contact with adult mental health services.

The 'elderly graduates' in contact with old age psychiatry in our study had significantly fewer unmet needs compared with those in contact with general adult psychiatry. This is in spite of the fact that total needs were not significantly different in the two groups. Tellingly the domains where unmet need was significantly more common in the general adult psychiatry group included management of medication, physical healthcare, domestic management, transport and housing. These were needs related to frailty that old age psychiatry services were more successful in addressing.

\section{Limitations}

This study reflects the work of the two services in a single innercity context. Feedback sessions for staff in the two services revealed

Table 2 Comparison of unmet needs of the old people with enduring mental illness who are in contact with adult general adult and old age psychiatry

\begin{tabular}{|c|c|c|c|}
\hline \multirow[b]{2}{*}{ Elderly Psychiatric Needs Schedule items } & \multicolumn{2}{|c|}{$n(\%)$} & \multirow[b]{2}{*}{$\begin{array}{l}\text { Odds ratio } \\
(95 \% \mathrm{Cl})\end{array}$} \\
\hline & $\begin{array}{l}\text { Old age psychiatry } \\
\qquad(n=34)\end{array}$ & $\begin{array}{l}\text { Adult general psychiatry } \\
\qquad(n=40)\end{array}$ & \\
\hline 1. Psychiatric assessment and treatment needs & $13(33)$ & $16(46)$ & $1.8(0.7-4.7)$ \\
\hline 2. Dementia assessment and management needs & $3(8)$ & $7(21)$ & $3.2(0.8-13.5)$ \\
\hline 3. Management of medication & $4(10)$ & $10(29)$ & $3.8(1.1-13.3)$ \\
\hline 4. Substance abuse services needs & $2(5)$ & $8(24)$ & $5.8(1.1-30)$ \\
\hline 5. Physical health needs & $7(18)$ & $13(38)$ & $2.9(1-8.5)$ \\
\hline 6. Communication needs & $2(5)$ & $6(18)$ & $4.1(0.7-22)$ \\
\hline 7. Mobility needs & $10(25)$ & $12(35)$ & $1.6(0.6-4.5)$ \\
\hline 8. Incontinence service need & $3(8)$ & $7(21)$ & $3.2(0.8-13.5)$ \\
\hline 9. Self-care needs & $6(15)$ & $10(29)$ & $2.4(0.8-7.4)$ \\
\hline 10. Domestic management needs & $4(10)$ & $11(32)$ & $4.3(1.2-15.1)$ \\
\hline 11. Food and eating needs & $2(5)$ & $7(21)$ & $4.9(0.9-25)$ \\
\hline 12. Safety and protection needs & $7(18)$ & $8(24)$ & $1.5(0.5-4.5)$ \\
\hline 13. Social activity needs & $17(43)$ & $17(50)$ & $1.4(0.5-3.4)$ \\
\hline 14. Day care needs & $16(40)$ & $17(50)$ & $1.5(0.6-3.8)$ \\
\hline 15. Money and benefits needs & $4(10)$ & $4(12)$ & $1.2(0.3-5.2)$ \\
\hline 16. Transport needs & $4(10)$ & $11(32)$ & $4.3(1.2-15.1)$ \\
\hline 17. Housing needs & $4(10)$ & $11(32)$ & $4.3(1.2-15.1)$ \\
\hline 18. Ethnic and cultural needs* & $2(5)$ & $4(12)$ & $2.5(0.4-14.8)$ \\
\hline 19. Management of patient's affairs & $1(3)$ & $5(15)$ & $6.7(0.7-61)$ \\
\hline 20. Other needs & $3(8)$ & $6(18)$ & $2.6(0.6-11.4)$ \\
\hline *Significant at $P<0.05$. & & & \\
\hline
\end{tabular}


the adult general psychiatry service was struggling with younger more disturbed patients who tend to divert time and resources away from older patients. There might be a need to repeat this study with a bigger sample that could include suburban and rural areas. The small sample also might have increased the risk of type II error, which also makes it necessary to recommend conducting further, and bigger, studies on this subject. Furthermore, the study is a cross-sectional assessment, which indicates the need for further follow-up studies in the field to make the finding more generalisable.

\section{Implications}

One of the main arguments that commissioners and local managers have put forward in support of the ageless services is that 'there is no evidence to say that old age services are better.' In spite of the limitations of this paper it is safe to conclude that the assumption implicit in the construction of 'ageless' services, in that working-age adult teams caring for people with enduring mental health problems in later life might be better than old age psychiatry services, is not supported. Furthermore, those calling for ageless services need to look at the lessons from the past century's introduction of generic practice in social care. The 1968 Seebohm Report on Social Services aimed at replacing 'a number of fragmented specialism with a confident generalism. ${ }^{16}$ Thompson, writing almost four decades later, highlighted the complications of such an approach in the form of making the demand for services infinite, ${ }^{17}$ needing a large undefined knowledge-base, ${ }^{17}$ creating a large bureaucratic organisation ${ }^{17}$ and resulting in a negative media and social image of the profession. ${ }^{17}$ The ageless services might also cause resources and personnel to move from less popular services to more popular ones such as children services. ${ }^{18}$ This paper is a small piece of evidence highlighting the risks to those patients with mental illness who are frail and elderly resulting from implementing ageless mental health services.

Walid Khalid Abdul-Hamid, MRCPsych, PhD, Centre for Psychiatry, Barts and the London, Queen Mary's School of Medicine and Dentistry and The Linden Centre, Broomfield, Chelmsford, UK; Kelly Lewis-Cole, PhD, clinical psychologist (independent), Andalusia, Spain; Frank Holloway, FRCPsych, Emeritus consultant psychiatrist, South London and Maudsley NHS Foundation Trust, Maudsley Hospital, London, UK; Ann Marisa Silverman (retired), South London and Maudsley NHS Foundation Trust, Maudsley Hospital, London, UK

Correspondence: Walid Khalid Abdul-Hamid, MRCPsych, PhD, The Linden Centre, Broomfield, Chelmsford CM1 7LF. Email: walid.abdul-hamid@nhs.uk

First received 7 Feb 2014, final revision 29 Jan 2015, accepted 30 Jan 2015

\section{References}

1 Warner J. Wither old age psychiatry? Int Psychoger 2014; 26: 1055-8.

2 Bailey S, Warner J, Farrar M, Dalton S, Anderson D, Burley C, et al. College Calls for Halt in Development of Ageless Mental Health Services. Royal College of Psychiatrists, 2013 (http://www.rcpsych.ac.uk/ usefulresources/rcpsychenewsletters/enewsletters2013/february2013/ agelessmentalhealthservices.aspx).

3 Warner J. Needs-based Criteria for Old Age Psychiatry Services Launched. Royal College of Psychiatrists, 2013.

4 Royal College of Psychiatrists. A Letter from Norman Lamb. Royal College of Psychiatrists, 2014 (https://www.rcpsych.ac.uk/discoverpsychiatry/ thepresidentsblog/letternormanlamb.aspx).

5 Green S, Girling DM, Lough S, Ng AMN, Whitcher SK. Service provision for elderly people with long-term functional illness. Psychiatr Bull 1997; 21 353-7.

6 McNulty S, Duncan L, Semple M, Jackson GA, Pelosi AJ. Care needs of elderly people with schizophrenia, assessment of an epidemiologically defined cohort in Scotland. Br J Psychiatry 2003; 182: 241-7.

7 Abdul-Hamid W, Johnson S, Thornicroft G, Holloway F, Silverman M. The needs of old people with enduring mental illness. Int J Geriatr Psychiatry 1999; 14: 984-5.

8 Jolley D, Kosky N, Holloway F. Older people with long-standing mental illness: the graduates. Adv Psychiatr Treat 2004; 10: 27-34.

9 Abdul-Hamid W, Lewis-Cole K, Holloway F, Silverman M. Older people with enduring mental illness: a needs assessment tool. Psychiatr Bull 2009; 33 : 91-5.

10 Arie T, Jolley DJ. Making services work: organization and style of psychogeriatric services. In The Psychiatry of Late Life (eds R. Levy, F. Post): 222-51. Blackwell, 1982.

11 Folstein M, Folstein S, McHugh P. "Mini-Mental State" a practical method of grading the cognitive state of patients for the clinicians. J Psychiatr Res 1975; 12: 189-98.

12 Ventura J, Green MF, Shanter A, Liberman RP. Training and quality assurance with the Brief Psychiatric Rating Scale: 'the drift buster'. Int J Methods Psychiatr Res 1993; 3: 221-44.

13 Yesavage JA, Brink TL, Rose TL, Lum O, Huang V, Adey M, et al. Developmenet and validation of a geriatric depression screenig scale: a preliminary report. J Psychiatr Res 1983; 17: 37-49.

14 Pattie AH, Gilleard CJ. Clifton Assessment Procedures for the Elderly. Stoughton Educational, 1979

15 Wing J. Meeting the needs of people with psychiatric disorders. Soc Psychiatry Psychiatr Epidemiol 1990; 25: 2-8.

16 Jones K. A History of the Mental Health Services. Routledge \& Kegan Paul 1972

17 Thompson N. Understanding Social Work (2nd edn). Palgrave, 2005.

18 Cassel CK. Researching the health needs of elderly people. BMJ 1994; 308 1655-6. 